\title{
Forty years of legal abortion: now it's time to review the law
}

\section{Ann Furedi}

\section{The aftermath of the Abortion Act 1967}

Since the Abortion Act $1967^{1}$ received Royal Assent on 27 October 1967, almost seven million women have benefited from safe legal abortion in Britain, 2,3 and tens of millions have been able to enjoy sex knowing that an unwanted pregnancy need not result in motherhood.

The Abortion Act 1967 has served women, and society, reasonably well. Despite being one of the most restrictive abortion laws in the developed world on paper, it is one of the most liberal in its interpretation. Although the Act does not formally permit abortion 'on request', that is close to what it allows in practice. Today, doctors can confidently refer women for abortion, believing that denying the request and compelling continuation of an unwanted pregnancy risks the woman's mental health. As the risks of abortion have reduced with advances in medical practice, the physical and mental risks of abortion have become relatively lower than advanced pregnancy and childbirth. ${ }^{4,5}$ Under these conditions, the 'continuance of the pregnancy' will always involve a relative risk of injury that is greater than if the pregnancy were terminated.

British law does not recognise a 'right' to abortion, however, and is often compared unfavourably with other countries in Europe that acknowledge women's rights. However, where abortion is conferred notionally as a 'right', it tends to be strictly qualified and limited to the early weeks of pregnancy. Often in practice, Continental access is more restricted than in Britain. For example, French and Italian law provide for abortion on request in early pregnancy, but severely limit later procedures. ${ }^{6} \mathrm{~A}$ major advantage of Britain's 1967 Act is that it draws no distinction between the grounds for abortion in the first or second trimester. Doctors are as free to refer women to end an unwanted pregnancy at 23 weeks' gestation as they are at 6 weeks. Given recently published evidence of the need for second-trimester services 7 this is a major benefit. Women are known to travel from European countries with codified legal 'abortion rights' to benefit from Britain's liberal access to services at later gestations.

The Abortion Act 1967 was a product of its time in not addressing women's right to abortion. David Steel's Bill reflected and codified the concerns of the pre-'feminist' 1960s and was shaped by contemporary debates. Although this was a time of social reform and liberalising of attitudes, the large-scale cohesion of what would become known as the 'Women's movement' - and the establishment's recognition of it - was some years away. In 1967, the Labour Government was seeking to promote a consensus that social problems could be solved through welfare policies. Abortion was framed as a means to help women who could not cope with pregnancy and motherhood.

The Act was essentially a means to minimise the numbers of 'unfit' mothers and 'unfit' children, rather than

J Fam Plann Reprod Health Care 2007; 33(3): 147-148

British Pregnancy Advisory Service (bpas),

Stratford-upon-Avon, UK

Ann Furedi, Chief Executive

Correspondence to: Ann Furedi, bpas, 4th Floor, AMEC House, Timothy's Bridge Road, Stratford-upon-Avon CV37 9BF, UK.

E-mail: ann.furedi@bpas.org to liberate women or to permit equality or human rights. There was more than a whiff of neo-Malthusianism in the air, articulated throughout the pages of medical journals and voiced in Parliament. Dr John Dunwoody, a Labour MP and general practitioner, expressed the sentiment of the times in arguing for legal abortion because: “... in many cases today when we have over-large families the mother is so broken down physically and emotionally ... that it becomes quite impossible for her to fulfil her real function, her worthwhile function as a mother holding together the family unit, so that all too often the family breaks apart, and it is for this reason that we have so many problem families". 8

Contemporary concern about 'unfit' parents, the emerging thalidomide crisis (which raised concern about the management of identified fetal abnormality) and the need to regulate abortions already taking place in Britain were the drivers to reform. Unsafe abortion was already a dangerous fact of life. Estimates as to how many illegal abortions occurred each year varied from $20000^{9}$ to 150000 . The treatment of clandestine abortion accounted for one-fifth of gynaecological admissions within the NHS. ${ }^{10}$ Maternal mortality due to illegal abortion was acknowledged to be unacceptably high. Unsurprisingly, legal abortion was seen as a solution to a public health problem rather than any expression of the right to choose.

The subsequent 40 years have seen fundamental changes in social attitudes and expectations and it is time to review our abortion law and bring it into line with modern views.

\section{The situation today and in the future}

Today, we expect to be able to plan our families. Society generally accepts that sex can be a celebration of love, comfort and intimacy rather than simply a means of procreation. We know that contraception methods and their users are not infallible, and so if we are to achieve planned parenthood then abortion is a necessary backup to birth control.

Society regards parenthood as a significant responsibility to be undertaken with forethought and consideration. These expectations do not easily sit alongside views that would compel women to have children that they do not want, and do not believe they can care for. One woman in three will seek termination of pregnancy before the age of 45 years. Although abortion is still stigmatised, it is now widely accepted as 'part of life'.

There is widespread public support for legal abortion among the public and policymakers. A weighted, representative survey of British public opinion carried out by Ipsos MORI in 2006 found that almost two-thirds (63\%) of respondents agreed that: "If a woman wants an abortion, she should not have to continue with her pregnancy".11 A recent Regulatory Impact Assessment, signed by the Secretary of State for Health, calculated the cost of severely restricting abortion as: “ $£ 750$ million a year net financial costs, high risk of up to 15 deaths a year, 15,000 extra teenage mothers a year, 12,000 children a year neglected/abused". 9

There has also been a sea change in the way people relate to the medical profession. A law that still places women in a position where they are supplicant to their doctors' judgements seems arcane and anachronistic in this context. 
The fact that British law de facto allows abortion on request is not an argument against reform. It is time to look ahead and frame what an abortion law should look like that could take us forward for the next 40 years. Such a law should reflect our social attitudes and views, ending the hypocrisy that pretends abortion is rare and attempts to 'ghettoise' it. We should not have to work around an Act that stigmatises abortion, setting it aside from other procedures and privileging doctors' opinions about unwanted pregnancy above those of the women who experience them.

Women deserve better: a modern, fit-for-purpose law accepting that restrictions on abortion should be solely to protect health. Current legal anachronisms about who provides abortions, and where they should be carried out, should be modernised to take account of new medical technologies and the developing role of nurses. Early medical abortion and manual vacuum aspiration is suited to nurse delivery and is practised successfully in the USA, South Africa and across the developing world.

The law should recognise that a decision about the future of a pregnancy should lie with the woman who carries it. Women are not less morally literate than doctors. They (we) can be trusted to make responsible, complex decisions about pregnancy. Given that someone has to make a decision about whether an unwanted pregnancy should be ended or continued, it is surely right that that someone should be the person most affected by the decision: the pregnant woman who will live with the consequences of the decision for the rest of her life.

The law should also be consistent with modern medical ethics, in that competent people can legitimately refuse to compromise their bodily integrity. In refusing a Caesarean section, a mentally competent woman may guarantee that she is not delivered of a living child, but she commits no crime in doing so. We may disagree with her decision, but it is her bodily autonomy that the law is concerned with. The law often requires us to distinguish between what is legal and what we think is right and wrong; but most of us accept that allowing un-consented medical intervention is a greater social evil than tolerating an occasional, unpalatable individual choice. So it should be with abortion.

What would this mean for legal reform? Arguably, a law that would explicitly allow abortion at the request of a woman because her pregnancy is unwanted; permit suitably qualified health care providers other than doctors to carry out abortions; remove 'class of place' restrictions; require the NHS to fund services to meet local demand; and remove the geographical anomaly that excludes Northern Ireland from the reach of the Abortion Act. More simply, Britain could look simply at decriminalising abortion. In Canada, abortion care is successfully managed under the Canada Health Act in the same way as any other necessary medical intervention.

In summary, a comprehensive parliamentary review of the abortion law is long overdue.

Statements on funding and competing interests

Funding None identified.

Competing interests The author is Chief Executive of a not-forprofit charity that provides abortion services.

\section{References}

1 The Abortion Act 1967. London, UK: HMSO, 1967

2 Abortion Statistics, England and Wales: 2005. http://www.dh.gov.uk/en/Publicationsandstatistics/Publications/ PublicationsStatistics/DH_4136852 [Accessed 2 May 2007].

3 Scottish Health Statistics 2005. http://www.isdscotland.org/ isd/files/mat_aas_table7.xls [Accessed 2 May 2007]

4 Royal College of Obstetricians and Gynaecologists (RCOG). The Care of Women Requesting Induced Abortion (Evidencebased Clinical Guideline No. 7). 2004; 25 http:// www.rcog.org.uk/resources/Public/pdf/induced_abortionfull.pdf [Accessed 2 May 2007].

5 Grimes DA. Estimation of pregnancy-related mortality risk by pregnancy outcome, United States, 1991 to 1999. Am J Obstet Gynecol 2006; 194: 92-94.

6 BBC News. Europe's abortion rules. February 2007. http://news.bbc.co.uk/1/hi/world/europe/6235557.stm [Accessed 3 May 2007].

7 Ingham R, Lee E, Clements S, Stone N. Second-trimester Abortions in England and Wales. April 2007. http://www.soton.ac.uk/lateabortionstudy/late_abortion.pdf [Accessed 3 May 2007].

8 Sheldon S. Beyond Control: Medical Power and Abortion Law. London, UK: Pluto Press, 1997; 21.

9 Department of Health. Partial Regulatory Impact Assessment: Prohibition of Abortion (Section 2.4). October 2005. http://www.dh.gov.uk/en/Publicationsandstatistics/Legislation/ Regulatoryimpactassessment/DH_4104022 [Accessed 3 May 2007].

10 Report of the Committee on the Working of the Abortion Act (Lane Committee). London, UK: HMSO, 1974; Vol. 1, paragraph 35.

11 Ipsos Mori Survey on Attitudes to Abortion. November 2006. http://www.ipsos-mori.com/polls/2006/bpas.shtml [Accessed 3 May 2007].

\section{BOOK REVIEW}

Lost: Illegal Abortion Stories. J Wainer. Melbourne, Australia: Melbourne University Press, 2006. ISBN: 0-5228-5231-9. Price: $£ 15.00$. Pages: 224 (paperback)

As Jo Wainer writes in her introduction: "Abortion is an act so laden with raw emotion that otherwise civilized societies would rather have mothers die than let women decide whether they will mother".

Jo Wainer was a university student when she became secretary of an abortion law reform association in Melbourne in the late 1960s, and met Bertram Wainer, a Scots-born general practitioner, who was shocked at the corrupt hierarchy of illegal abortion provision that existed in Victoria at that time. Together, and with the help of friends and supporters, they began to gather evidence about the conditions under which poor women particularly obtained abortions, and they mounted some of the first test cases to establish what constituted lawful abortion in Victoria. They endured threats to their livelihoods and their lives, and their story is fascinating. Jo Wainer isn't focusing on that story in this book. She is recounting the stories of women who came forward to Dr Wainer in the 1980s to give their personal accounts of illegal abortion, so that their experiences would not be lost. It is an oral history that reminds readers how little power women had in their relationships with men and family, and the often-devastating consequences of that. Women are frank about their relationships, their emotions and their own shortcomings. There are also some contributions from hospital staff, recounting the public hospital response to the consequences of illegal abortions, and from the mother of a young woman who died.

Abortion is now widely available in Australia, but access is difficult in many areas and it remains on the criminal codes in several states. In the USA and elsewhere, women's rights to safe abortion are constantly being eroded. This book reminds us that where state law makes abortion illegal, abortions continue to happen, but women are exposed to humiliation, fear and danger.

Reviewed by Pauline McGough, MRCOG, MFFP Locum Consultant in Sexual and Reproductive Health, Glasgow, UK

\section{FOCUS ON ABORTION}

2007 marks the 40th anniversary of the Abortion Act 1967. In view of this fact, the July issue of the Journal includes a greater than usual number of commissioned articles and submitted papers on abortion and related topics. 